\title{
The Impact of Theory X, Theory Y and Theory Z on Research Performance: An Empirical Study from A Turkish University
}

\section{Oya Tamtekin Aydin*}

Okan University, Institute of Social Sciences, Istanbul, Turkey.

*Corresponding Author: Email: oyatamtekin@gmail.com

\begin{abstract}
The purpose of this study is to find the Impact of Theory $\mathrm{X}$, Theory $\mathrm{Y}$ and Theory $\mathrm{Z}$ on research performance of Foundation University members in Turkey on the number of articles published in Science Citation Index and Social Science Citation Index. The study was conducted on 101 academics in a Turkish Foundation University. The following results are obtained from the study: i) The perception of academics on the effect of Theory X management style which assumes that people dislike work and will avoid it if possible and most people must be "coerced, controlled, directed, and threatened with punishment to get them" to work on research performance is negative ii) The perception of academics on the effect of Theory Y management style which assumes that the people they supervise are as committed to work and as capable of finding solutions to work-related problems as they are themselves (McGregor, Douglas, 1960) and Theory Y managers also assume that people inherently prefer to work rather than not to work on research performance is positive. iii) The perception of academics on the effect of Theory $\mathrm{Z}$ management style which thinks workers will be participating in the decisions of the company to a great degree, one author is careful to point out that the employees must be very knowledgeable about the various issues of the company, as well as possessing the competence to make those decisions on research performance is positive.
\end{abstract}

Keywords: Research Performance Theory X, Theory Y, Theory Z.

\section{Introduction}

In the world there are a lot of ranking systems to evaluate the universities. Some of the most important ranking systems are Higher Education Evaluation and Accreditation Council of Taiwan (HEEACT), The Academic Ranking of World Universities (ARWU), The World University Ranking commonly known as The Shanghai Ranking. One of the most important criteria used to assess universities is research performance of academics.

For instance for the HEEACT rankings criteria: Research productivity is $20 \%$ (the number of published articles of the last 11 years is $10 \%$ and the number of articles of the current year is $10 \%)$. Research impact is weighed at $30 \%$ (number of citations of the last 11 years is $10 \%$, the number of citations of the last two years is $10 \%$, and the average number of citations of the last 11 years is 10\%). Research excellence is $40 \%$ ( $t$ he h-index of the last two years is $20 \%$, the number of highly-cited papers is $15 \%$, and the number of articles of the current year in highimpact journals is 15\%) and unfortunately Turkish Universities are not in the HEEACT Ranking. The other significant ranking system is The Academic Ranking of World Universities (ARWU), commonly known as The Shanghai
Ranking. It is a publication that was founded and compiled by the Shanghai Jiaotong University to rank universities globally. The ranking compares higher education institutions worldwide according to a formula that took into account alumni winning Nobel Prizes and Fields Medals is $10 \%$, staff winning Nobel Prizes and Fields Medals is 20\%, highly-cited researchers in 21 broad subject categories is $20 \%$, articles published in the journals Nature and Science is $20 \%$, the Science Citation Index and Social Sciences Citation Index is $20 \%$ and the per capita research performance of an institution $10 \%$. Turkish Universities are the last place in ARWU Ranking [1].

The purpose of this study, like the other article "The Impact of Herzberg Theory on Research Performance" is to reveal the factors affecting research performance of academics. But in this article the factors affecting research performance of academics are explained by Theory X, Theory Y And Theory Z management styles instead of Herzberg Theory. Both of articles the perception of academics is used to explain $t \mathrm{~h} e$ factors affecting research performance. 


\section{Literature Review}

\section{$\mathrm{X}, \mathrm{Y}$ and $\mathrm{Z}$ Theory}

In 1960 Douglas Mc Gregor defined contrasting assumptions about the natüre of humans in the work place. These assumptions are the basis of Theory X and Theory Y teachings. Mc-Gregor believed that the average manager operated under a set of assumptions he called classical management, or Theory X management: People dislike work and will avoid it if possible. Most people must be "coerced, controlled, directed, and threatened with punishment to get them" to work [2-3]. The average human prefers to be directed, wishes to avoid responsibility, has little ambition, and wants security. These assumptions lead managers to deny employees control over their work environment and to use methods of influence that are direct and harsh. Theory $\mathrm{X}$ managers emphasize the chain of command, reward-or-punishment motivational techniques, and close supervision of subordinate behavior along rigidly defined behavioral parameters. McGregor argued that classical management practice was hindering rather than helping organizations solve prob- lems, meet goals, and deliver a product in a reliable manner [2-3]. A Theory X management style assumes that people are interested in safety and physiological needs rather than higher needs, but McGregor believed that workers in the 1950s had moved beyond lower needs and were seeking to meet social or esteem needs [2-3].

Based on that conclusion, he proposed a new set of managerial assumptions, which he called Theory Y management: Theory $\mathrm{Y}$ managers assume that the people they supervise are as committed to work and as capable of finding solutions to work-related problems as they are themselves [2-3]. Theory Y managers also assume that people inherently prefer to work rather than not to work. As a result, they tend to push responsibility for work down the chain of command. They grant employees autonomy within their areas of accountability, and they structure work so that subordinates have ample opportunity to identify problems and find creative solutions to them. Theory $\mathrm{Y}$ managers attempt to structure the work environment so that employee goals coincide with organizational goals, resulting presumably in greater creativity and productivity [4].In 1981 another theory which has emerged, and deals with the way in which workers are perceived by managers, as well as how managers are perceived by workers, is William Ouchi's "Theory Z". Often referred to as the "Japanese" management style, Theory Z offers the notion of a hybrid management style which is a combination of a strict American management style (Theory A) and a strict Japanese management style (Theory J). This theory speaks of an organisational culture which mirrors the Japanese culture in which workers are more participative, and capable of performing many and varied tasks. Theory $\mathrm{Z}$ emphasises things such as job rotation, broadening of skills, generalisation versus specialisation, and the need for continuous training of workers [5]. Much like McGregor's theories, Ouchi's Theory Z makes certain assumptions about workers.

Some of the assumptions about workers under this theory include the notion that workers tend to want to build co-operative and intimate working relationships with those that they work for and with, as well as the people that work for them. Also, Theory $\mathrm{Z}$ workers have a high need to be supported by the company, and highly value a working environment in which such things as family, cultures and traditions, and social institutions are regarded as equally important as the work itself. These types of workers have a very well developed sense of order, discipline, moral obligation to work hard, and a sense of cohesion with their fellow workers. Finally, Theory $\mathrm{Z}$ workers, it is assumed, can be trusted to do their jobs to their utmost ability, so long as management can be trusted to support them and look out for their well being [6] .

One of the most important principles of this theory is that management must have a high degree of confidence in its workers in order for this type of participative management to work. While this theory assumes that workers will be participating in the decisions of the company to a great degree, one author is careful to point out that the employees must be very knowledgeable about the various issues of the company, as well as possessing the competence to make those decisions. This author is also careful to point out, however, that management sometimes has a tendency to underestimate the ability of the workers to effectively contribute to the decision making process [7]. But for this reason, Theory $\mathrm{Z}$ stresses the need for enabling the workers to become generalists, rather than specialists, and to increase their knowledge of the company and its processes through job rotations and continual training. In fact, promotions tend to be slower in this type of setting, as workers are given a much longer opportunity to receive training and more time to learn the intricacies of the company's operations. 
The desire, under this theory, is to develop a work force, which has more of a loyalty towards staying with the company for an entire career, and be more permanent than in other types of settings. It is expected that once an employee does rise to a position of high level management, they will know a great deal more about the company and how it operates, and will be able to use Theory $\mathrm{Z}$ management theories effectively on the newer employees [5].

\section{Comparison of $\mathrm{X}, \mathrm{Y}$ and $\mathrm{Z}$ Theories}

For Theory $\mathrm{X}$, workers are assumed to be lazy while theory $\mathrm{Y}$, says that workers are more participative and creative. $\mathrm{Y}$ and $\mathrm{Z}$, assumptions about people are much productive and their managers are human oriented than $\mathrm{X}$ theory, each theory exhibits managers' and workers' ability to increase their productivity in their job. Monetary rewards can also be a prime motivator to make Theory $\mathrm{X}$ workers produce more. In Theory Y, man will exercise self-direction and self-control in the service of objectives to which he is committed. William Ouchi's Theory Z, believes that people are innately self motivated to not only do their work, but also are loyal towards the company. Theories $\mathrm{Y}$ and $\mathrm{Z}$, they both see managers like "coaches", helping the workers to be more productive. They both are more group oriented but the Theory $\mathrm{X}$ is more individual oriented. Theory X leaders are more authoritarian who have task oriented view while Theory $\mathrm{Y}$ leaders are more participative. Theory $\mathrm{X}$ and Theory $Y$ have a much more formal leadership style than do Theory $\mathrm{Z}$ managers. In Theory Z, managers trust their workers and Theory $\mathrm{Z}$ leaders have human oriented view. In terms of authority, in the case of Theory $\mathrm{X}$, the manager would seem to keep most of the power and authority. In the case of Theory Y, the manager would take suggestions from workers, but would keep the power for making decision. In Theory Z, the manager's ability to exercise power and authority comes from the worker's trusting management. In conflict situations: $\mathrm{X}$ and $\mathrm{Y}$, type of manager might be more likely to exercise a great deal of "power" based conflict resolution style, especially with the Theory $\mathrm{X}$ workers. Theory Y workers might be given the opportunity to exert some flexible "negotiating" strategies to solve their own differences. While conflict in the theory Z, would involve a great deal of communication, collaboration, discussion and negotiation.

\section{Research Performance}

Academic performance is a complex concept for which no objective indicators exist and "the context and process through which indicators of performance are arrived at, and the subsequent use to which they are put, are judged to be as important as the information which each indicator conveys". The other study says that the literature on the quality and creativity of science suggests that, among others, multi-level communication, continuity in funding, and peace and quiet in working environments, are factors which support creativity and productivity [8-10]. Auranena and Nieminenb consider that no straightforward mechanism from funding incentives to research activity. Incentives sometimes balance and sometimes enforce each other. Thus, one needs to study both the allocation mechanisms of core funds and the share of external competitive funding in order to assess the overall degree of competition in the system of university funding. University research funding and publication performance [11]. Marinova and Newman's research shows that there are at least two necessary pre-conditions for Australia to have a healthy, strong and world-class university research sector. Firstly, adequate resources should be provided to match and recognise its current achievements. Secondly, the funding model that is used some very good recommendations are made by CHASS should allow for diversity and flexibility to properly reflect the complexity of academic world. The changing research funding regime in Australia and academic productivity [12]. Zainab considers research productivity to be reporting and publishing research findings in (inter)national journals, conference presentations, patent registration, impact factors and reviews [13]. The University of Utah defines research productivity as cited publication of library or field journal papers and book chapters [14]. It has been recommended that the indicator of getting published in leading journals should have a higher weight than other indicators. Research productivity as an average number of published research report in the last two years [15]. Regarding gender, there are significant differences between males and females on number of published articles and impact factors [16]. Research publication in the university is a major or most significant indicator of academic staff productivity. It may be pointed out that, research publication in any field of specialization provide current information for growth, progress, development and an improvement of society [17].

\section{Methodology}

Sample 
The sample of this study was selected in a foundation university in İstanbul. The sample consists of a total of 101 individuals from this foundation university including doctor, assistant professor, associate professor and professor.

\section{Hypotheses}

H1: The perception of academics on the effect of Theory $\mathrm{X}$ on research performance is negative.
H2: The perception of academics on the effect of Theory $\mathrm{Y}$ on research performance is positive.

H3: The perception of academics on the effect of Theory $\mathrm{Z}$ on research performance is positive.

\section{Measures}

The questionnaire, a 20-items scale, is designed to examine factors affecting research performance of faculty members of a foundation university by using McGregor Theory X,Y William Ouchi's Theory Z. Fourteen questions of these subscales were measured on

Table 1: One-sample statistics with variables name and category according to McGregor theory $x$, theory Y, Ouchi's theory Z

\begin{tabular}{|c|c|c|c|c|c|c|}
\hline & Name of variables & $\begin{array}{c}\text { Kinf of } \\
\text { assumption }\end{array}$ & $\mathbf{N}$ & Mean & $\begin{array}{c}\text { Std. } \\
\text { deviation }\end{array}$ & $\begin{array}{c}\text { Std. erro } \\
\text { mean }\end{array}$ \\
\hline VAR00001 & $\begin{array}{l}\text { Human being does not like } \\
\text { working }\end{array}$ & Theory X & 101 & 4,4257 & ,51665 & ,05141 \\
\hline VAR00002 & $\begin{array}{l}\text { Human being prefers to be } \\
\text { directed and wishes to avoid } \\
\text { responsibility }\end{array}$ & Theory X & 101 & 4,5545 &, 51914 & 05166 \\
\hline VAR00003 & $\begin{array}{l}\text { Most people must be controlled } \\
\text { and directed }\end{array}$ & Theory X & 101 & 4,4851 &, 52180 & ,05192 \\
\hline VAR00004 & $\begin{array}{l}\text { Employees are motivated by } \\
\text { extrinsic rewards such as money, } \\
\text { promotions }\end{array}$ & Theory X & 101 & 4,4851 &, 50227 & ,04998 \\
\hline VAR00005 & The average human likes working & Theory Y & 101 & 4,4851 &, 50227 & ,04998 \\
\hline VAR00006 & $\begin{array}{l}\text { The average human being not } \\
\text { only accepts but also seeks } \\
\text { responsibility }\end{array}$ & Theory Y & 101 & 4,5545 & ,49950 & 04970 \\
\hline VAR00007 & $\begin{array}{l}\text { Most people have self-direction } \\
\text { and self-control in order to } \\
\text { achieve goals }\end{array}$ & Theory Y & 101 & 4,5644 &, 51799 &, 05154 \\
\hline VAR00008 & $\begin{array}{l}\text { Employees are motivated by } \\
\text { instinctive motivational factors } \\
\text { not only money or promotions }\end{array}$ & Theory Y & 101 & 4,6139 & ,48929 & ,04869 \\
\hline VAR00009 & Long-term employment & Theory Z & 101 & 4,4851 &, 52180 & ,05192 \\
\hline VAR00010 & Career paths & Theory Z & 101 & 4,4950 &, 50247 &, 05000 \\
\hline VAR00011 & Informal control & Theory Z & 101 & 4,4752 &, 50188 & 04994 \\
\hline VAR00012 & Group decision making & Theory Z & 101 & 4,4752 &, 50188 & 04994 \\
\hline VAR00013 & Employer must be trust & Theory Z & 101 & 4,4554 &, 50049 & 04980 \\
\hline VAR00014 & Work and life balance & Theory Z & 101 & 4,3168 & ,46756 &, 04652 \\
\hline
\end{tabular}


Table 2: One-sample test with variables name and category according to McGregor theory X, theory Y, Ouchi's theory z

\section{Test Value $=4$}

Names of variables

Kind of assumption

VAR00001

Human being does not like working

Human being prefers to be directed and wishes to avoid responsibility

VAR00003 Most people must be controlled and directed

VAR00004 Employees are motivated by extrinsic rewards such as money, promotions

VAR00005 The average human likes working

Theory Y

, 000

4,48515

4,3860

4,5843

Theory Y

, 000

4,55446

4,4558

4,6531 accepts but also seeks responsibility

VAR00007 Most people have self-direction and self-control in order to achieve goals

VAR00008 Employees are motivated by instinctive motivational factors not only money or promotions

VAR00009 Long-term employment

VAR00010 Career paths

VAR00011 Informal control

VAR00012 Group decision making

VAR00013 Employer must be trust

VAR00014 Work and life balance
Theory Y

, 000

4,56436

4,4621

4,6666

Theory Y

, 000

4,61386

4,5173

4,7105
Difference

Upper

4,5277

4,6569

4,5882

4,5843

$\begin{array}{lrrrr}\text { Theory Z } & , 000 & 4,48515 & 4,3821 & 4,5882 \\ & , 000 & 4,49505 & 4,3959 & 4,5942 \\ \text { Theory Z } & & & & \\ & , 000 & 4,47525 & 4,3762 & 4,5743 \\ \text { Theory Z } & , 000 & 4,47525 & 4,3762 & 4,5743 \\ & & & \\ \text { Theory Z } & , 000 & 4,45545 & 4,3566 & 4,5542 \\ \text { Theory Z } & , 000 & 4,31683 & 4,2245 & 4,4091 \\ \text { Theory Z } & & & & \end{array}$

Theory Z a five-point Likert type scale, with responses ranging from 1 (strongly disagree) to 5 (strongly agree). Questions 15-19 were demographics. These questions were not used in this study. They will be used for forthcoming studies. The last question of the questionnaire is open-ended. The questionnaire was distributed to the sampled academic staff and an interval of two weeks was allowed for them to complete and return the questionnaire.

\section{Research Findings}

One-Sample Statistics show the mean score of variables. The variables of Theory $\mathrm{X}, \mathrm{Y}$ and $\mathrm{Z}$ are as follows:

VAR00001: Human being does not like working. VAR00002: Human being prefers to be directed and wishes to avoid responsibility.
VAR00003: Most people must be controlled and directed.

VAR00004: Employees are motivated by extrinsic rewards such as money, promotions.

VAR00005: The average human likes working.

VAR00006: The average human being not only accepts but also seeks responsibility

VAR00007: Most people have self-direction and self-control in order to achieve goals.

VAR00008: Employees are motivated by instinctive motivational factors not only money.

VAR00009: Long-term employment is important.

VAR00010: Career paths is important.

VAR00011: Informal control is important.

VAR00012: Group decision making is important.

VAR00013: Employer must be trust to their employees is important.

VAR00014: Work and life balance is important. 
If the means of variables are bigger than the test value which is defined as 4, the hypotheses are accepted; if the means of variables are not bigger than the test value, the hypotheses are not accepted. In order to investigate the hypotheses of the study, t-test is applied and the results are given in Table 1 and Table 2.

As shown in Table 1 the means of all variables are bigger than the test value. Variables 1-4 are about Theory $\mathrm{X}$ and these variables support $\mathrm{H} 1$, variables 5-8 are about Theory $\mathrm{Y}$ and they support $\mathrm{H} 2$, variables 9-14 are about Theory $Z$ and these variables support H3.The eighth variable is the most important variable whereas the fourteenth variable is the least significant one.

One-Sample $\mathrm{T}$ Test is used to analyze the hypotheses and the results are given in Table 2 . $\mathrm{H} 1$ argues that the perception of academics on the effect of Theory $\mathrm{X}$ on research performance is negative. H2 argues that the perception of academics on the effect of Theory $\mathrm{Y}$ on research performance is positive. H3 argues that the perception of academics on the effect of Theory $\mathrm{Z}$ on research performance is positive. As it is shown in Table 2, and for all 14 variables, the $p$ value of them is smaller than the significance level $(p=0.000<0.05)$ and so it can be said that the results of this study supported all three hypotheses.

\section{Conclusion}

The study analyzed the relationships among Theory X/Y/Z assumptions and research performance of academics. This article provides the administrators guidance about how to improve the research performance of academics. In this study the management styles which affect

\section{References}

1. Aydin TO (2012) International Review of Management and Marketing, 2(2):106-11.

2. McGregor D (1960) The Human Side of Enterprise. New York: McGraw-Hill, 11-64.

3. Gurus on People Management, Five Douglas McGregor (1906-1964), Thorogood Publishing Ltd.

4. McGregor D (1967) The Professional Manager. New York: McGraw Hill, 77.

5. Luthans F (1989) Organisational Behaviour. New York: McGraw-Hill.

6. Massie Joseph L, Douglas J (1992) Managing: A Contemporary Introduction. Englewood Cliffs: Simon \& Schuster Company. the research performance of academics have been explained by Theory X, Y and Z and confirmed by the perceptions of academics of a foundation university in Turkey. According to the study Theory $X$ effects research performance in a negative way whereas Theory $\mathrm{Y}$ and $\mathrm{Z}$ have a positive impact. Also, the study shows that management style proves to be a significant factor on the research performance outlined by answers to open ended questions. Academics state the following as main factors for poor research performance: lack of proficiency in foreign language (23\%), long evaluation process and biased evaluation committees (\%13), ineffective management styles (52\%) such as budget deficits, motivational problems, limited time due to administrative roles, and personal problems $(12 \%)$ [18-25].

However, one should not generalize one assumption to fit all situations. The main focus should still be on individual needs and differences. There are still people that would perform much better under autocratic managers whereas others would perform much better under democratic managers. As academics are highly educated people, we cannot apply theory $\mathrm{X}$ here. Theory $\mathrm{Y}$ and $\mathrm{Z}$ are more applicable to these group of professionals. Academics would perform poorly under autocratic managers.

This article proves that management style has positive effect on research performance. Another article stressed the importance of motivation factors and how they have a positive impact on research performance [1]. Both management styles and motivation are important factors for academics in Turkey's foundation based universities as measured by number of articles published in Science Citation Index and Social Science Citation Index.

7. Bittel Lester R (1989) The McGraw-Hill 36-Hour Management Course. New York: McGraw-Hill.

8. Amabile TM (1994) The Atmosphere of Pure Work: Creativity in Research and Development. In: Shadish WR, Fuller S (Eds.), The Social Psychology of Science. The Guilford Press, New York, 316-28.

9. Gulbrandsen JM (2000) Research Quality and Organizational Factors: An Investigation of the Relationship. Department of Industrial Economics and Technology Management, Norwegian University of Science and Technology, Trondheim.

10. Hurley J (1997) Organization and Scientific Discovery. John Wiley\&Sons, Chichester.Phillimore J (1985-86) University 
11. research performance indicators in practice: the University Grants

12. Auranena O, Nieminenb M (2010) Technology and Innovation Studies (TaSTI), Institute for Social Research, Finland Research Policy 39: 822-34.

13. Marinova D, Newman P (2008) The Curtin University Sustainability Policy (CUSP) Institute.

14. Zainab AN (1999) Personal academic and departmental correlates of research productivity: A Review of Literature. Malaysian Journal of Library and Information Science, 4(2):73-110.

15. Ransdell LB (2001) Using the proceed model to increase productivity in health education faculty.The International Electronic Journal of Health Education, 4:276-82.

16. Sax LJ, Hagedorn LS, Arredond M, Dicrisi FA (2002) Faculty Research Productivity: Exploring the Role of Gender and Family-Related Factors. Research Higher Education,43:423-46.

17. Turner L, Mairesse J (2003) Explaining Individual Productivity Difference in Scientific Research Productivity: How Important are Institutional and Individual Determinants?

18. Usang B, Basil A, Lucy U (2007) Academic staff research productivity: a study of universities in south-south zone of Nigeria. Educational Research and Review, 2(5):103-08.
19. Barney J (2004) Introduction: William Ouchi's Theory Z: How American business can meet the Japanese Challenge, Academy of Mangement Executive, 18(4).

20. Bittel Lester R (1989) The McGraw-Hill 36-Hour Management Course. New York: McGrawHill."Going from A to Z: Thirteen Steps to a Theory Z Organization,” Management Review, p.8-16.

21. Gulbrandsen M, Smeby JC (2005) Industry funding and university professors'research performance. Research Policy, 34 (6): 932-50.

22. Committee's evaluation of British universities, Research Policy 18: 255-71.

23. McGregor D (1944) Conditions of effective leadership in the industrial organization. Journal of Consulting Psychology 8(2):55-63.

24. Micheal Bobic, William D, A kind word for theory $\mathrm{x}$ : or why so many newfangled management techniques quickly fail. Journal of Public Administration Research and Theory,13(3):239-64.

25. Morton Donald J (1975) Theory Y is not participative management, Human Resource Management, Winter, p. 25-28.

26. Sager Kevin L (2008) An Exploratory Study of the Relationships Between Theory X/Y Assumptions and Superior Communicator Style, Management Communication Quarterly, 22: 288-311. 
Available online at www.managementjournal.info 